\title{
Juventudes Camponesas das Comunidades Zé Alves e Laranjal no Município de Poconé-MT: dilemas entre ficar e sair do campo ${ }^{i}$
}

\author{
Jucieli Bertoncello ${ }^{1}$, Michelle Tatiane Jaber da Silva ${ }^{2}$, Regina Aparecida da Silva ${ }^{3}$ \\ ${ }^{1}$ Universidade do Estado de Mato Grosso - UNEMAT. Departamento de Pedagogia. Rodovia Juara Brasnorte, Km 02. Juara - \\ MT. Brasil. ${ }^{2,3}$ Universidade Federal do Estado de Mato Grosso - UFMT. \\ Autor para correspondência/Author for correspondence: profjucieli@gmail.com
}

\begin{abstract}
RESUMO. Este artigo resulta e desmembra da pesquisa de mestrado intitulada "Conflitos socioambientais e mudanças climáticas sob o olhar das juventudes camponesas de PoconéMato Grosso", teve como objetivo compreender as percepções das juventudes sobre os conflitos socioambientais e as mudanças climáticas existentes na comunidade tradicional "Nossa Senhora de Lurdes" (conhecida como Zé Alves) e na comunidade "Remanescente de Quilombo Laranjal", ambas localizadas no município de Poconé-MT. Nessa trama, também articulamos reflexões para compreender os dilemas entre "ficar e sair" vivenciados pelas juventudes, uma vez que as juventudes camponesas de ambas comunidades estão sendo invisibilizadas pelo avanço do agronegócio que transformam os bens naturais em recursos, para atender a lógica economicista, impossibilitando a permanência nos territórios. A proposição investigativa apoiou-se no método qualitativo, tendo como táticas metodológicas o Mapa Social. Para obter as informações, foram realizados sete trabalhos de campo, dois seminários de mapeamento, doze entrevistas semiestruturadas com as juventudes, ademais fontes secundárias (relatórios, artigos e censos) sobre as comunidades pesquisadas. Compreendemos que a migração campo-cidade estão relacionadas, principalmente com a ausência de escolarização e oportunidades de trabalho e renda, além da não efetivação das políticas públicas pensadas para essa realidade.
\end{abstract}

Palavras-chave: Comunidades Camponesas, Juventudes Camponesas, Dilemas entre Ficar e Sair do Campo.

\begin{tabular}{l|l|l|l|l|l|l|} 
RBEC & Tocantinópolis/Brasil & v. 5 & e8255 & $10.20873 /$ uft.rbec.e8255 & 2020 & ISSN: 2525-4863 \\
\hline
\end{tabular}




\title{
Youth Peasant Communities Zé Alves and Laranjal in the municipality of Poconé, MT: dilemmas between staying and leaving from countryside
}

\begin{abstract}
This article results and dismembered the master's research on "environmental conflict and climate change under the gaze of peasant youths Poconé, Mato Grosso," aimed at understanding perceptions of youths on environmental conflicts and existing climate change on our traditional community Lady of Lourdes (known as Zé Alves) and the Remnant Quilombo community Orangery, both located in the municipality of Poconé, MT. In this plot also articulate reflections to understand the dilemmas of "getting in and out" experienced by youths since the peasant youths of both communities are being made invisible by agribusiness advances that transform natural goods resources, to meet the economic perspective, making it impossible to remain in the territories. The investigative proposition relied on the qualitative method, with the methodological tactics the Social Map. For information were conducted seven field work, two mapping seminars, twelve semi-structured interviews with the youths, besides secondary sources (reports, articles and census) of the surveyed communities. We understand that the rural-urban migration are mainly related to lack of education and job opportunities and income, as well as non-execution of public policies thought to this reality.
\end{abstract}

Keywords: Peasant Communities, Peasant Youths, Dilemmas Between Staying and Leaving from Countryside. 


\section{Comunidades Campesinas juveniles Zé Alves y Laranjal en el municipio de Poconé, MT: dilemas entre quedarse y dejando el campo}

RESUMEN. Este artículo es el resultado y desmembrado. La investigación de la maestría en "conflicto ambiental y el cambio climático bajo la mirada del campesino jóvenes Poconé, Mato Grosso," dirigido a la comprensión percepciones de los jóvenes en conflictos ambientales y el cambio climático existente en nuestra comunidad tradicional Señora de Lourdes (conocido como Zé Alves) y la comunidad Remanente Quilombo invernadero, ambos ubicados en el municipio de Poconé, MT. En esta trama también articular reflexiones para entender los dilemas de "entrar y salir" experimentada por los jóvenes ya los jóvenes campesinos de ambas comunidades se hacen invisibles por los avances agroindustriales que transforman los recursos naturales de mercancías, para cumplir con el punto de vista económico, por lo que es imposible a permanecer en los territorios. La propuesta de investigación se basó en el método cualitativo, con las tácticas metodológicas del mapa social. Para obtener información se llevaron a cabo el trabajo de campo y siete, dos seminarios de mapeo, doce entrevistas semiestructuradas con los jóvenes, además de fuentes secundarias (informes, artículos y censo) de las comunidades encuestadas. Entendemos que la migración rural-urbana están relacionados principalmente con la falta de educación y oportunidades de empleo e ingresos, así como la no ejecución de las políticas públicas cree que esta realidad.

Palabras clave: Comunidades Campesinas, Jóvenes Campesinos, Los Dilemas Entre Quedarse y Dejando Campo. 


\section{Introdução}

Esta pesquisa foi realizada em duas comunidades localizadas aproximadamente a $110 \mathrm{~km}$ da capital Cuiabá, na MT-451 (Rodovia Adauto Leite), município de Poconé/MT, sendo a comunidade tradicional "Nossa Senhora de Lurdes" (conhecida como Zé Alves), localizada às margens da MT-451 no km 17 e a "Comunidade Remanescente de Quilombo Laranjal", às margens da estrada vicinal do Buriti, a $15 \mathrm{~km}$ da rodovia asfaltada MT451, com entrada para a comunidade no $\mathrm{km} \mathrm{13.} \mathrm{Ambas} \mathrm{fazem} \mathrm{parte} \mathrm{de} \mathrm{um} \mathrm{conjunto}$ de aproximadamente 70 comunidades localizadas na transição entre o Cerrado e o Pantanal, ficando assim, conhecida por seus/suas moradores/as que são quilombolas, tradicionais e assentados como "Comunidades do Cerrado do Pantanal".

Em meio a essa diversidade de dois biomas, o avanço acelerado dos latifúndios de monoculturas tem colocado em risco a biodiversidade e a existência dessas comunidades e dos grupos presentes neste território. Muitos se sentem ameaçados, pois, esse modelo econômico continua reproduzindo ações de violência, opressão, exploração e expulsão dos “... povos do campo, das florestas e das águas ...” (Carneiro \& Neto, 2013, p. 09), como o sistema latifundiário instituído durante o
Brasil colônia, após o fim do regime das sesmarias. Esse sistema desde quando foi criado tem conseguido estabelecer o controle territorial impedindo que esses grupos tenham acesso e consigam permanecer nos territórios, mantendo viva sua cultura, identidade e a forma de relacionar-se com a natureza.

$\mathrm{Na}$ tentativa de permanecerem nos territórios do campo, as comunidades inseridas no Cerrado do Pantanal que possuem uma cultura e identidade muito particular, assim como os diferentes grupos sociais mapeados por Silva (2011), estão se organizando coletivamente e resistindo/reexistindo a todos os tipos de violência e violação de direitos provocados por esse “... moderno-colonial de acumulação capitalista" (Porto-Gonçalves et al., 2016, p. 85), que devasta os territórios por meio dos desmatamentos para a introdução das monoculturas, e as atividades como pecuária e extrativismo mineral já consolidada nesta região.

Em Laranjal o quadro de injustiças e conflitos existem/avançam há aproximadamente 30 anos, quando fazendeiros ocuparam as terras com a ajuda de autoridades locais, jagunços e funcionários públicos que eram por direito dos quilombolas. Atualmente, essas famílias encontram-se espremidas entre as 
cercas dos grandes latifúndios e a estrada que dá acesso ao quilombo, ficando assim, impossibilitadas de realizar atividades produtivas para subsistência e comercialização. Em Zé Alves, por terem acesso a terra conseguem manter a identidade com o território que habitam, no entanto, sentem-se ameaçados pelo avanço do agronegócio na região.

Em meio a essa realidade distinta entre Zé Alves e Laranjal, temos como sujeito dessa pesquisa as juventudes ${ }^{\mathrm{ii}}$ camponesas invisibilizadas nos territórios pelo avanço das monoculturas que transformam a natureza em mercadoria, impossibilitando a permanência nos territórios. Em Zé Alves, as juventudes que permanecem na comunidade estão estudando ou ajudando a família no plantio, na colheita e na comercialização dos produtos como hortaliças, verduras, frutas, doces, cana-de-açúcar e seus derivados - melado, rapadura e açúcar mascavo. A grande maioria encontra-se organizado por meio do associativismo e cooperativismo para que assim, possam plantar e colher, e consequentemente permanecer na comunidade e sobreviver da terra.

Já as juventudes de Laranjal sofrem com a expropriação do território ocorrido há aproximadamente 30 anos, quando fazendeiros ocuparam as terras com a ajuda de autoridades locais, jagunços e funcionários públicos que eram por direito dos quilombolas. Atualmente, essas famílias, juntamente com as juventudes, encontram-se espremidas entre as cercas dos grandes latifúndios e a estrada que dá acesso ao quilombo, ficando assim, impossibilitados de realizar atividades produtivas para subsistência e comercialização. Consequentemente, as juventudes deixam a escola muito cedo para vender a força de trabalho e ajudar no sustento da família como empreiteiro, mensalista ou diarista para os donos dos grandes latifundiários da região.

Nessa perspectiva, Molina (2015, p.13), ressalta que as transformações no campo, trazidos pela lógica de acumulação do capital, representadas pelo agronegócio e de suas monoculturas de exportação transforma “... os alimentos em commodities intensificam, por diversas estratégias, a superexploração dos camponeses e suas famílias, e, entre eles, dos jovens". Assim,

... abordar a juventude camponesa exige compreender o território do campo para muito além de um espaço de produção agrícola, em contraposição à produção industrial, de uma cultura rústica versus cultura moderna, ou de um lugar sem trabalho, para um espaço onde se pode produzir, para viver com dignidade, para citar algumas dicotomias. O campo como lugar de vida, não se configura estando em extinção, mas sim como território 
onde se forma a juventude camponesa, de múltiplas possibilidades, de novas relações entre seres humanos e entre estes e a natureza, de novas articulações e possibilidades de produção/reprodução da vida. (Leão \& Antunes-Rocha, 2015, p. 26).

Molina (2015, p. 15) afirma que "ficar ou sair não é simplesmente uma escolha ao bel-prazer dos jovens, mas uma difícil decisão permeada por condicionantes estruturais sobre os quais os jovens individualmente não conseguem incidir no sentido de superá-las". Consideramos que ainda existem jovens que fazem a opção de continuarem a vida no campo, como é o caso de alguns jovens de Zé Alves e Laranjal. Porém, as condições de vida no campo, a falta de acesso às políticas públicas específicas para a educação do campo, a falta de alternativas profissionais que possam garantir emprego e renda na agricultura familiar ou fora dela (Freitas \& Santos, 2015), somadas às dificuldades vivenciadas por seus familiares fazem com que muitos tenham que sair em busca de novas oportunidades na cidade.

Para uma melhor compreensão desta pesquisa que resulta de uma dissertação de mestrado, primeiro apresentamos as escolhas metodológicas, posteriormente as políticas públicas para as juventudes camponesas, algumas percepções sobre os dilemas entre sair e ficar vivenciados pelas juventudes camponesas das comunidades Zé Alves e Laranjal, e por fim, as considerações dessa trama vivenciadas pelas juventudes dessas duas Comunidades localizadas no Cerrado do Pantanal.

\section{Escolhas metodológicos da pesquisa}

A metodologia é entendida como o fio condutor da pesquisa, é a explicação detalhada de todas as ações a serem desenvolvidas, ou seja, os instrumentos, as técnicas, o tempo previsto, a equipe de pesquisadores/as, o tratamento dos dados que compõem os resultados, enfim, é o momento de apresentar detalhadamente todo caminho percorrido. Em relação ao fazer pesquisa, Brandão (2003, p. 10) afirma que existem algumas diferenças sobre "... como se pensa o fazer pesquisa científica e como se faz a pesquisa científica que se pensa". Deve haver outra bastante próxima entre "como se faz uma pesquisa e como nós vivemos a pesquisa que fazemos". Compreendemos que não existe um manual a seguir acerca do processo investigativo durante a pesquisa, mas a escolha do método e da metodologia são fatores determinantes para se chegar ao que foi proposto. Brandão (2003, p. 23) acrescenta que nesse fazer e pensar, a pesquisa "em uma sociedade marinada pela desigualdade, nenhuma pesquisa é isenta de neutralidade". 
Na concepção de Minayo (2009), a metodologia é o caminho do pensamento, ou seja, a prática exercida sobre uma determinada realidade, a ela é incluída a teoria da abordagem (o método), os instrumentos da pesquisa (as técnicas) e a criatividade do pesquisador (sua experiência, sua capacidade e sua sensibilidade). Portanto, a metodologia “... é muito mais que técnicas. Ela inclui as concepções teóricas da abordagem, articulando-se com a teoria, com a realidade empírica e com os pensamentos sobre a realidade" (ibidem, p. 15). A realidade deste contexto pesquisado carrega as marcas da violência, da violação de direitos, de injustiças sociais e ambientais e de inúmeros conflitos socioambientais silenciados. Assim, utilizamos nesta pesquisa de mestrado o método qualitativo acompanhado da metodologia denominada Mapa Social (Silva, 2011).

$\mathrm{O}$ método qualitativo trabalha com um universo muito particular de aspirações, crenças, valores e atitudes, aprofunda-se no mundo das significações, das ações humanas, respondendo a questões muito particulares das relações sociais estabelecidas em sociedade que não pode ser quantificada (Minayo, 2009). Esse conjunto de fenômenos é entendido “... como parte da realidade social, pois, o ser humano se distingue não só por agir, mas por pensar sobre o que faz e por interpretar suas ações dentro e a partir da realidade vivida e partilhada com seus semelhantes" (ibidem, p. 21).

Esse método faz com que o/a pesquisador/a tenha uma melhor compreensão do sujeito estudado, permitindo a participação em todo o processo, ou seja, é ao mesmo tempo o sujeito e o objeto da pesquisa. Possibilitando ainda uma relação de proximidade entre pesquisador e pesquisados, os pesquisados estão livres para dialogar com o pesquisador sobre os assuntos relacionados com o objeto de estudo, além disso, as respostas são subjetivas, já que o propósito não é a representatividade numérica, mas compreender um determinado grupo social. Ao contrário do que muitos pensam, o envolvimento entre o/a pesquisador/a e pesquisados/as é de fundamental importância. Para Moreira (2017, p. 6566), os participantes da pesquisa “... são parceiros/as com quem estabelecemos uma relação de horizontalidade, quebrando a lógica hierárquica da ciência moderna de sujeito (pesquisador/a) e objeto (pesquisado)".

A metodologia "Mapa Social" tem como objetivo dar visibilidade aos diferentes grupos sociais de Mato Grosso, 
baseia-se na autoidentificação e nas autonarrativas dos próprios sujeitos pesquisados (Silva, 2011; Jaber-Silva, 2012). Os mapas criados na perspectiva dos movimentos sociais, das populações tradicionais, das comunidades impactadas pelos projetos desenvolvimentistas torna-se um mecanismo de luta e resistência (Porto, Pacheco \& Leroy, 2013).

Assim, buscando responder aos objetivos propostos nesta pesquisa, três momentos distintos que se complementam foram realizados. Primeiro, foi realizado o I Mapeamento Social do Cerrado do Pantanal seguido das leituras teóricas; o segundo momento mais introspectivo, foram realizadas as entrevistas com um roteiro de perguntas semiestruturadas com 12 jovens, sendo 6 da comunidade Zé Alves e 6 da comunidade Laranjal, além das entrevistas com moradores/as antigos/as para compreender o contexto histórico das comunidades, posteriormente no terceiro momento realizamos o II Mapeamento Social do Cerrado do Pantanal.

\section{Políticas públicas para as juventudes camponesas}

Historicamente, a inclusão das juventudes nas políticas públicas brasileiras é recente, mais recente ainda refere-se às políticas para as juventudes camponesas. Freire e Castro (2010, p. 150) afirmam que esse movimento só começa a ganhar força a partir da década de 1990 quando “... se configurou o foco do poder público sobre a juventude no Brasil, que políticas são formuladas e implementadas, que a sociedade se engaja com mais vigor no debate e na intervenção social". Conforme o Guia de Políticas Públicas de Juventude (Brasil, 2006, p. 05) “entender as singularidades $\mathrm{e}$ as peculiaridades das juventudes e garantir direitos a essa geração são fatores fundamentais para consolidar a democracia no Brasil, com inclusão social”. Ressalta também que:

As políticas públicas passaram a incluir as questões relacionadas à juventude, de forma mais consistente, por motivos emergenciais, já que os jovens são os mais atingidos pelas transformações no mundo do trabalho e pelas distintas formas de violência física e simbólica que caracterizam o século XXI. (Brasil, 2006, p. 06).

Consideramos que na tentativa de garantir direitos para as juventudes, muitos foram os programas, projetos e ações pensados pelo Governo Federal, porém, muitas dessas ações ainda encontram-se somente no papel. Segundo o Guia de Políticas Públicas (2006) existia 19 executados por diferentes Ministérios, que constituía a Política Nacional de Juventude no País. Porém, apenas três programas estavam vinculados ao acesso à terra, 
sendo: o Programa Nacional de Crédito Fundiário (Programa Nossa Primeira Terra) desde 2003; o Programa Pronaf Jovem - criado em 2004 e o Programa ProJovem Campo - Saberes da Terra (2005), e dois ao acesso à educação, entre eles: o Programa Nacional de Educação na Reforma Agrária (PRONERA) e o Programa Nacional de Educação do Campo (PRONACAMPO).

O Programa Nossa Primeira Terra correspondia a uma linha de financiamento dentro do Programa Nacional de Crédito Fundiário, destinada aos jovens agricultores e estudantes de Escolas Agrotécnicas e centro familiares de formação por alternância, com idade entre 18 a 29 anos que queiram permanecer no campo juntamente com seus familiares ao invés de migrarem para as grandes cidades, promovendo assim, o empoderamento e incentivo à sucessão no campo (Brasil, 2006).

O Pronaf Jovem configura-se como uma linha de financiamento do Programa Nacional de Agricultura Familiar, criada para atender aos filhos dos agricultores entre 16 e 25 anos, que tenham concluído ou estejam cursando o último ano em centros familiares rurais de formação por alternância, ou em escolas técnicas agrícolas de nível médio ou que tenham participado de curso ou estágio de formação profissional, incentivando a se manterem e permanecerem no campo (Pronaf, 2004).

O Programa ProJovem Campo Saberes da Terra visava oferecer qualificação profissional e escolarização aos jovens de 18 a 29 anos, que não concluíram o ensino fundamental, contribuindo para o acesso e a qualidade da educação à essa parcela historicamente excluídas do processo educacional, respeitando as características, necessidades e pluralidade de gênero, étnico-racial, cultural, geracional, política, econômica, territorial e produtivas (Brasil, 2006). Tínhamos também o PRONERA que era uma Política Pública que visava garantir a implementação e manutenção da Educação do Campo, e o PRONACAMPO, que consistiu em um conjunto de ações articuladas para o apoio e implementação das políticas de educação do campo nos sistemas de ensino (Porto, 2016).

Consideramos que apesar da existência dos programas, a grande maioria dos jovens que tentaram permanecer no campo não tem ou não tiveram acesso a esses programas. Ferreira e Alves (2009) ressaltam que os programas ainda eram insuficientes para a produção de mudanças significativas perante os desafios referentes ao acesso ao trabalho e educação no campo, ou seja, não possibilitam opções 
viáveis para a construção de seus projetos de vida. Para Molina (2015), a impossibilidade do acesso a terra, a ausência de políticas públicas que lhes garantam condições mínimas de sobrevivência nos territórios de origem, pressionam a continuarem rotas de migração em busca de espaço para sua reprodução material.

\section{Juventudes camponesas: dilemas entre ficar ou sair}

Queremos ficar aqui até o resto da nossa vida, nascemos efomos criados aqui, nós queremos viver aqui [...] (Jaime Santana Filho, Comunidade Zé Alves).

Nos caminhos percorridos por Zé Alves e Laranjal, buscou-se conjuntamente com as percepções das juventudes sobre os conflitos socioambientais e as mudanças climáticas; compreender quais fatores têm influenciado a permanência ou saída das juventudes das comunidades pesquisadas. Consideramos que aos jovens das comunidades pesquisadas e tantos outros espalhados pelo território brasileiro foi e continua sendo negado o direito de escolher entre ficar ou sair do campo. Assim, podemos mencionar que as questões imbricadas entre ficar ou sair são bem mais complexas do que a simples lógica naturalizada na grande maioria das pesquisas que evidencia somente o desejo dos jovens em não permanecer no campo.

Eu já saí e voltei, quando tinha dificuldade na casa ou no sitio, eu era o mais velho então era eu que saía para trabalhar, ver se conseguia alguma coisa para manter eles aqui, quando conseguia um emprego o que eu ganhava dividia, ficava com metade e mandava metade pra casa. Daí para cá ficamos nesse processo migratório, nunca paro. Antigamente jovens da minha idade tinha quase uns trinta, hoje estão quase todos na cidade, mas é difícil um final de semana que esses caras não estão aqui. $\mathrm{O}$ mais engraçado que o sonho de todos eles é ganhar dinheiro e vir embora, ninguém fala que quer morar na cidade, eu vou ganhar um dinheiro e montar um negocinho e voltar para a comunidade (Edmar Viana Pereira Zé Alves).

Eu sempre morei aqui, eu fui morei seis meses para lá e voltei, porque não me acostumei cidade, eu não gostei, não acostumei, eu trabalhava no mercado. Agora, agora eu não pretendo voltar para terminar os estudos" ... Tem muito jovem indo embora do campo. Os jovens têm ido embora por falta de serviço, de estudo, tem bastante jovens sem estudar, prefere trabalhar ali na fazenda do que estudar (Maria do Carmo Moura Ferreira Araújo Laranjal).

$\mathrm{Na}$ tentativa de desconstruir essa imagem desinteressada pelo campo serão apresentadas as narrativas que expressam o sonho e o desejo das juventudes de Zé Alves e Laranjal em permanecerem na comunidade, no entanto, com a falta de políticas públicas, acesso à terra, ao lazer, à educação e ao trabalho, muitos acabam 
sendo obrigados a migrarem em busca de novas oportunidades. Há uma tendência no contexto brasileiro, marcado por exclusões e desigualdades com as populações que vivem no campo, como se fosse uma parte atrasada e fora de lugar no almejado projeto de modernidade, assim não haveria necessidade de políticas públicas específicas, a não ser do tipo compensatório à sua própria condição de inferioridade (Fernandes, Cerioli \& Caldart, 1998).

Para superar essa realidade faz-se necessário intensas lutas coletivas que pressionem o Estado e o façam agir por meio das políticas públicas específicas que lhes garantam condições mínimas de sobrevivência nos territórios de origem, criando de fato condições para que os mesmos possam realmente escolher entre viver no campo (Molina, 2015) ou não. Em Zé Alves alguns jovens encontraram no associativismo e no cooperativismo uma forma de obter renda para permanecerem no campo.

A cooperativa fez com que nós ficássemos na comunidade, a gente acreditou que dava certo comercializar através da cooperativa (Edmar Viana Pereira - Zé Alves).

A educação da escola e a formação do movimento, formação de base que a gente fala na Pastoral da Juventude, pela CPT, incentivaram que era possível sobreviver aqui sem você ter que ir para a cidade, a gente foi pegando os conhecimentos também, muitas viagens, muita articulação em rede, a gente conseguiu buscar esses caminhos da comercializar por meio desses programas do Governo Federal, antes era 4.500 o PAA, logo em seguida em 2009 entrou o PNAE, só que antes de tudo isso nós já trabalhava com a feira, em 2000 nós fazia rapadura e entregava para o mercado. Então começamos a ver que a rapadura era um potencial, sempre plantamos mandioca, horta a mamãe, produzimos banana e começamos a ir para a feira em Poconé, depois começamos atender alguns mercados, levava os produtos para a feira para atender os feirantes e um pouco a mais para atender o mercado, e aí a gente começou a ter essa renda, nós como jovem não tinha aquela vidona, mas pelo menos para atender as necessidades básicas. Depois começamos a ir para outras comunidades incentivando $o$ associativismo e o cooperativismo (Jaime Santana Filho - Zé Alves).

Para Leão e Antunes-Rocha (2015, p. 21) estar organizado em associativismo e cooperativismo significa “... organizar sua existência na possibilidade de produzir e reproduzir sua vida no território camponês, entendido aqui como um espaço material/imaterial de produção da vida ..." e da cultura. As narrativas das juventudes de Zé Alves demonstram que é possível permanecer no campo e sobreviver da produção no próprio território, no entanto, nem todos possuem acesso à terra e aos programas governamentais evidenciados como o PNAE (Programa Nacional de Alimentação Escolar) e PAA (Programa de Aquisição de Alimentos). 
Segundo Souza-Esquerdo e Bergamasco (2014), historicamente, a agricultura familiar sempre foi excluída das políticas públicas, uma vez que os recursos eram centrados apenas na propriedade privada e na monocultura de exportação. O programa PAA estimula a produção pela agricultura familiar e incentiva a comercialização para que populações em situação de insegurança alimentar tenham acesso aos alimentos de qualidade, e o PNAE obriga as escolas estaduais e municipais a utilizar no mínimo $30 \%$ dos recursos financeiros repassados pelo Fundo Nacional de Desenvolvimento da Educação (FNDE) para adquirir alimentos da agricultura familiar.

Diferente de Zé Alves, as juventudes de Laranjal expropriados do território juntamente com seus familiares não têm acesso a esses programas, assim são obrigados a vender a força de trabalho para os latifundiários ou migrarem para a cidade em busca de melhores condições de vida.

Eu já fui para cidade, voltei porque estava cansado da cidade, lá eu só trabalhava. Estudei até a quarta série, eu parei porque não tinha condição, tinha que trabalhar. Eu comecei a trabalhar na fazenda com 16 anos. Eu até tenho vontade de estudar, mas não acho mais tempo, oportunidade de ir estudar (Gonçalo Araújo Laranjal).

... eu já fui para a cidade fiquei três meses, mas não me acostumei. Eu estudei até o quarto ano, tinha que trabalhar para ajudar no sustento da casa, comecei com 16 anos na fazenda, na diária e nunca assinou carteira. Chega no final do ano não tem direito a nada (Almir José da Costa - Laranjal).

As narrativas demonstram as dificuldades das juventudes quilombolas em alcançar os níveis elevados de escolaridade, as situações de injustiças e a violação de direitos. Para compreender a realidade das juventudes do campo, suas perspectivas futuras, é preciso levar em conta que estão inseridos em uma estrutura social baseada pela concentração de terra e por uma concepção de desenvolvimento voltado para a produção agrícola de exportação. Esse modelo de desenvolvimento tem contribuído para a saída das juventudes para os centros urbanos em busca de qualificação profissional, trabalho e renda para ajudar a família. As narrativas acima demonstram a realidade de dois irmãos que tiveram que escolher entre estudar e trabalhar.

Outro aspecto importante a ser sublinhado, refere-se ao fato de trabalharem desde os 16 anos sem carteira assinada, revelando um quadro de injustiça social e econômica que perduram há aproximadamente dez anos. Diante dessa situação, os jovens nada podem fazer, já que vender a mão de obra para os latifundiários ainda é a única opção de emprego na região. Apesar da existência de 
políticas públicas para agricultura familiar, esporte, cultura e educação, essas ainda não chegaram no quilombo. Esse modelo de sociedade vigente baseado no acúmulo de capital por uma pequena parcela da população gera “... desigualdade na distribuição da riqueza material e simbólica produzida no campo, gerando um quadro de resultados sociais e educacionais extremamente desfavoráveis ..." (Wollz et al., 2014, p. 106) para quilombolas, indígenas, camponeses dentre outros que habitam nos territórios.

Entendemos que os jovens quando deixam o campo não estão negando sua identidade, não saem porque preferem viver na cidade, mas pela desvalorização ou ausência de trabalho, precariedade ou inexistência de escolas, falta de oportunidade de qualificação profissional, perspectiva de vida no campo, e ainda pelos preconceitos e estereótipos que multiplicam-se cotidianamente. Em relação aos preconceitos, os jovens da comunidade Laranjal sofrem por ser do campo, ser negro e ser quilombola.

Moreira (2017) afirma que os quilombolas padecem com consequências sociais e ambientais deste sistema econômico desigual, as discriminações, exclusões e preconceitos evidenciam a relação entre classe social/poder econômico e preconceito/racismo, tornando-se impossível falar de realização integral da cidadania e plenitude da democracia em um sistema capitalista meritocrático que expropria e expulsa os jovens do campo.

Eu penso em mudar para a cidade porque aqui não tem como continuar, aqui não tem como fazer uma faculdade. Meus pais querem que eu faça a distância, mas vamos ver o que fica mais fácil. Eu tenho vontade de ir para cidade por causa dos estudos ... alguns jovens acabam o ensino médio e acaba ficando por aqui, outros vão embora, a maioria vai embora porque quer trabalhar (Jane de Oliveira - Zé Alves).

Os jovens vão embora por causa do emprego, eles vão procurar emprego melhor na cidade, porque aqui não tem, quando termina fica em casa parado, não tem o que fazer. Minha irmã foi embora porque ela quer estudar, só que ele ainda não conseguiu, mas tá fazendo um curso para poder trabalhar. Tem muita gente indo embora, os filhos vão e os pais fica. Antes os pais não deixava ir, agora deixa para os filhos ter um futuro melhor ... (Ireni da Silva Castro - Laranjal).

A migração campo-cidade está relacionada principalmente a ausência de oportunidade de escolarização e trabalho, a Cooperativa Mista dos Produtores Rurais de Poconé - COMPRUP ${ }^{\mathrm{iii}}$ representa para as juventudes uma possibilidade de melhores condições de vida em um tempo futuro. O descaso em efetivar políticas públicas eleva a situação de miséria das juventudes. Dados divulgados pelo 
programa "Brasil sem Miséria" apontam que de um total de 8,2 milhões de jovens do campo, 2,3 milhões vivem em situação de miséria, com uma renda mensal de aproximadamente 70 reais ou menos (Wollz et al., 2014). Para os autores a desvalorização da produção familiar causada pela produção em grande escala, o avanço do agronegócio, a distribuição desigual da riqueza material $\mathrm{e} a$ desvalorização simbólica dos diferentes grupos sociais nos territórios produzem efeitos sociais e educacionais desfavoráveis para os jovens que tentam viver no e do campo.

Historicamente, as populações que vivem no campo foram amplamente excluídas de atenção por parte das políticas globais e mesmo específicas para o campo (Faria \& Alves, 2015, p. 156), principalmente quando se trata das políticas educacionais. Desta forma, a educação ofertada no campo que se iniciou nos anos de 1930, se intensificou nos anos de 1950-1960, e se estendeu até os anos de 1970 desconsiderava os saberes do campo e considerava os interesses do mundo capitalista.

Apenas na década de 1980 com o Movimento dos Trabalhadores Rurais Sem Terra (MST), que nasce com o apoio de Igreja Católica, da Comissão Pastoral da Terra - CPT e os Sindicatos Rurais, inicia- se o processo de redemocratização do país e as lutas se fortalecem, esse movimento passou a exigir das autoridades uma Educação do Campo, que se contrapunha a educação rural vigente (Arroyo \& Fernandes, 1999; Porto, 2016).

Afirmam que esse movimento convoca a I $^{\text {iv }}$ Conferência Nacional por uma Educação Básica do Campo, a conferência aconteceu em Luziânia-GO, de 27 a 30 de julho de 1998 e contou com a participação dos seguintes movimentos sociais: Conferência Nacional dos Bispos do Brasil (CNBB), o Movimento dos Trabalhadores Rurais Sem Terra (MST), a Organização das Nações Unidas para a Infância (UNICEF), a Organização das Nações Unidas para a Educação Cultura (UNESCO) e a Universidade de Brasília (UNB).

Durante a Conferência a principal discussão era como garantir que todas as pessoas que vivem no meio rural possam ter acesso a uma educação de qualidade, e voltada para os interesses da vida no campo, além disso, ficou decidido que a expressão campo substituiria o termo meio rural tendo como objetivo:

... incluir no processo da conferência uma reflexão sobre o sentido atual do trabalho camponês e das lutas sociais; e culturais dos grupos que hoje tentam garantir a sobrevivência desse trabalho. Mas, quando se discutir a educação do campo se estará tratando da educação que se 
volta ao conjunto dos trabalhadores e das trabalhadoras do campo, sejam os camponeses, incluindo os quilombolas, sejam as nações indígenas, sejam os diversos tipos de assalariados vinculados à vida e ao trabalho no meio rural. Embora com essa preocupação mais ampla, há uma preocupação especial com o resgate do conceito de camponês. Um conceito histórico e político...". (Fernandes, Cerioli \& Caldart, 1998, p. 09).

Os movimentos sociais fortaleceram a educação do campo que deixou de ser educação rural para se tornar educação do campo para os povos do campo, com o campo e não para o campo, assim, a educação do campo nasce em contraposição à educação rural. Uma educação que seja: "No: o povo tem direito a ser educado no lugar onde vive; Do: o povo tem direito a uma educação pensada desde o seu lugar e com a sua participação, vinculada à sua cultura $\mathrm{e}$ às suas necessidades humanas e sociais" (Caldart, 1999, p. 25).

Já a II Conferência Nacional por um uma educação do Campo conforme Caldart (2013) foi realizada em julho de 2014, com mais de mil participantes representados por 39 entidades, incluindo representantes de órgão de governo, organizações sindicais de trabalhadores/as rurais e de professores/as, além dos movimentos sociais camponeses e escolas de comunidades do campo. A conferência teve como lema "Educação do Campo: direito nosso, dever do Estado", onde expressou a “... luta pelo acesso dos trabalhadores do campo à educação é específica, necessária e justa, deve se dar no âmbito do espaço público, e o Estado deve ser pressionado para formular políticas que a garantam massivamente, levando à universalização real e não apenas princípios abstratos" (ibidem, p. 260). Apesar da existência desses movimentos de luta, as comunidades pesquisadas continuam lutando por uma educação do campo.

Hoje a nossa luta é por uma educação do campo, uma educação que respeite os conhecimentos, a cultura de acordo com a nossa realidade. Só que hoje, eu vejo que a educação que as nossas crianças estão recebendo, como uma educação no campo, uma educação jogada. Para começar, eles saem da comunidade para ir para um pólo, uma educação pensando pelo capitalismo que busca desarticular o campo ... Nós queremos uma educação voltada para a nossa realidade, nós lutamos para essa educação que é do campo, de acordo com a nossa realidade. A educação contribuiu e é fundamental para a permanência dos jovens no campo, a educação do jovem tem que caminhar junto com os demais afazeres, articulada com todos os segmentos do campo, a educação na associação, na cooperativa, na produção, no conhecimento de pesquisa, tem que estar junta. A gente vai adquirir conhecimentos, mas a gente tem que retornar para a base esse conhecimento, tem que desenvolver aqui na comunidade, na cooperativa, na associação. Eu não vejo outro caminho se não for pela educação, a única saída nossa e da nação é ter 
conhecimento, e a educação ela está em primeiro lugar ... (Jaime Santana Filho - Zé Alves).

Diante da narrativa das juventudes, pode-se reafirmar que a educação ofertada no campo, na grande maioria, encontra-se desvinculada dos interesses do campo. A luta não é para “... uma escola no campo ou para o campo, nem uma escola da cidade no campo, mas uma escola do campo, com a cultura, os valores, a luta do campo" (Arroyo \& Fernandes, 1999, p. 10), uma educação que não ocorra apenas entre quatro paredes, quatro horas por dia e cinco dias por semana, mas uma educação pensada a partir das vivências cotidianas, vinculada na associação, na cooperativa, na produção e em todos os segmentos da comunidade.

\section{Algumas considerações da pesquisa}

Consideramos nesta pesquisa que o dilema entre sair ou ficar no campo vivenciado pelas juventudes das comunidades Zé Alves, Laranjal e tantas outras espalhadas pelo território matogrossense, não estão relacionadas ao fato de negarem sua identidade camponesa, mas a falta de acesso a terra para plantar e colher, trabalho, educação e as políticas públicas que garantam a permanência e a sobrevivência na terra.
Assim, os sujeitos jovens que permanecem no campo são obrigados a silenciar e a venderem sua força de trabalho como mensalistas ou diaristas por míseros salários para os donos dos latifúndios. Outros tentaram e tentam reconstruir suas histórias na cidade, mas a vida agitada dos grandes centros faz com que voltem para a comunidade, permanecendo em condições de vulnerabilidade.

Portanto, as cenas dessa história revelam sempre um sofrimento de sujeitos concretos que perdem seus territórios, suas casas e precisam resistir para reconstruir novas histórias. Desse modo, os caminhos e descaminhos trilhados nessa pesquisa com as juventudes não foram suficientes para mudar a realidade desse grupo, que grita pela terra para poder nela permanecer, mas possibilitaram desconstruir essa imagem das juventudes desinteressadas pelo campo como muitos estudos têm afirmado.

\section{Referências}

Arroyo, M. G., \& Fernandes, B. M. (1999). A educação básica e o movimento social do campo. Brasília: Articulação Nacional Por uma educação básica do campo.

Brandão, C. R. (2003). A pergunta a várias mãos: a experiência da pesquisa no trabalho educativo. São Paulo: Cortez. 
Brasil. (2006). Guia de Políticas Públicas de Juventude. Brasília: Secretaria Geral da Presidência da República.

Carneiro, F. F., \& Netto, G. F. (2013). Prefácio. In Porto, M. F., Pacheco, T., \& Leroy, J. P. (2013). Injustiça Ambiental e Saúde no Brasil: o mapa de conflitos. Rio de Janeiro: FIOCRUZ.

Caldart, R. (2013). Educação do Campo. In Caldart, R. S. et al. (Orgs). Dicionário da Educação do Campo (pp. 257-272). 2. ed. 2. reimp. Rio de Janeiro, São Paulo: Escola Politécnica de Saúde Joaquim Venâncio, Expressão Popular.

Caldart, R. (1999). A escola do campo em movimento In Benjamin, C., \& Caldart, R. (Orgs.). Projeto popular e escolas do campo: Por uma educação do campo (pp. 26-57). Brasília: Articulação nacional da Educação do campo.

Faria, I., \& Alves, A. N. (2015). A emergência da questão quilombola e a educação da juventude do campo. In Leão, G., \& Antunes-Rocha, M. I. (Orgs). Juventudes do campo (pp. 149-166). 1. ed. Belo Horizonte: Autêntica.

Fernandes, M. B., Cerioli, P. R., \& Caldart, R. S. (1988). (Orgs.). Por uma educação do campo. In Conferência Nacional por uma Educação Básica do Campo. Brasília. Anais... Brasília: Associação Brasileira de Educadores Lassalista, Revista AEC e UNESCO.

Ferreira, B., \& Alves, F. (2009). Juventude rural: alguns impasses e sua importância para a agricultura. In Castro, J., Abrahão, A., Luseni M. C., \& Andrade, C. C. (Orgs.). Juventude e políticas sociais no Brasil (pp. 243-258). Brasília: Ipea.

Freitas, G. V., \& Santos, I. F. (2015). Juventudes das Escolas Família Agrícola de Minas Gerais: desafios e possibilidades na perspectiva da inserção profissional. In
Leão, G., \& Antunes-Rocha, M. I. (Orgs.). Juventudes do campo (pp. 167-183). 1. ed. Belo Horizonte: Autêntica.

Freire, J. C. S., \& Castro, E. M. R. (2010). Políticas públicas, juventude e Educação para a sustentabilidade: Saberes da terra em foco. In Molina, M. C. (Org). Educação do Campo e Pesquisa II: questões para reflexão (pp. 150-160). Brasília: MDA/MEC (Série NEAD Debate; 20).

Jaber-Silva, M. (2012). O mapeamento dos conflitos socioambientais de Mato Grosso: denunciando injustiças ambientais $e$ anunciando táticas de resistência (Tese de Doutorado). Universidade Federal de São Carlos, São Carlos.

Leão, G., \& Antunes-Rocha, M. I. (2015). Juventudes no/do campo: questões para um debate. In Leão, G., \& Antunes-Rocha, M. I. (Orgs). Juventudes do campo (pp. 1727). 1. ed. Belo Horizonte: Autêntica.

Novaes, R. (1998). Juventude/juventudes? Em Comunicações ISER, (50), ano 17, Rio de Janeiro: ISER.

Novaes, R. (2006). Os jovens de hoje: contextos, diferenças e trajetórias. In Almeida, M. I. M., \& Eugênio, F. (Orgs.). Culturas Jovens: novos mapas do afeto (pp. 105-120). Rio de Janeiro: Jorge Zahar.

Molina, M. C. (2015). Prefácio. In Leão, G., \& Antunes-Rocha, M. I. (Orgs). Juventudes do campo. 1. ed. Belo Horizonte: Autêntica.

Moreira, D. L. (2017). Território, luta e educação: dimensões pulsantes nos enfrentamentos dos conflitos socioambientais mapeados no Quilombo de Mata Cavalo (Dissertação de Mestrado). Universidade Federal de Mato Grosso, Cuiabá. 
Minayo, M. C. (2009). (Org.). Pesquisa social: teoria, método e criatividade. 29. ed. Petrópolis: Vozes.

Porto, I. (2016). Concepções e percepções de educação do campo na escola municipal boa esperança Sorriso - MT (Dissertação de Mestrado). Universidade Federal de Mato Grosso, Cuiabá.

Porto, M. F., Pacheco, T., \& Leroy, J. P. (2013). Injustiça Ambiental e Saúde no Brasil: o mapa de conflitos. Rio de Janeiro:

Fiocruz. https://doi.org/10.7476/9788575415764

Porto-Gonçalvez, C. W. et al. (2016). Os cerrados e os fronts do agronegócio no Brasil. In Canuto, A., Luz, C. R. S., \& Andrade, T. V. P. (Orgs.). Conflitos no Campo - Brasil 2016 (pp. 74-85). Goiânia: CPT Nacional.

Pronaf. Plano safra para a agricultura familiar 2003-2004. Brasília, 2003. Recuperado de: https://cms20.happybiz.com.br/Arquivos/E mpresa_020CONTEUDO_00000043_Ane xos/Original/020000000430031_0.pdf.

Acesso em: 11 Ago. 2020.

Souza-Esquerdo, V. F. (2014). Bergamasco, Sônia M. P. P. Análise Sobre o Acesso aos Programas de Públicas da Agricultura Familiar nos Municípios do Circuito das Frutas. RESR, 52, 205-222. https://doi.org/10.1590/S010320032014000600011

Silva, R. A. (2011). Do invisível ao visível: o mapeamento dos grupos sociais do estado de Mato Grosso - Brasil (Tese de Doutorado). Universidade Federal de São Carlos, São Carlos.

Wollz, L. E. B. et al. (2014). As infâncias e as brincadeiras das crianças do campo. In Wollz, L. E. B. (Orgs.). Percepções de infância e juventude no campo (pp. 71-
104). Curitiba, PR: CRV. https://doi.org/10.24824/978858042890.2.

\footnotetext{
${ }^{\mathrm{i}}$ Pesquisa com resultados parciais publicado como resumo expandido em anais recuperado de: http://anais.anped.org.br/regionais/sites/default/files /trabalhos/5/3380TEXTO_PROPOSTA_COMPLETO.pdf
}

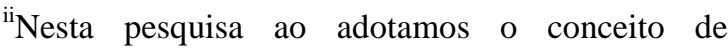
"juventudes" temos como embasamento os estudos de Novaes $(1998,2006)$ que destaca que o processo de construção da categoria juventude está intrinsecamente ligado aos aspectos sociais, econômicos, culturais e políticos que permeiam a sociedade, dessa forma o conceito de juventude pode estar relacionado a diversos fatores que influenciam em sua definição. Novais $(1998,2006)$ também aponta que a partir dos anos de 1980 e 1990, o debate sobre a juventude no Brasil trouxe o olhar para além dos cortes etários, assim não se fala mais em juventude, mas em juventudes no plural. A partir dessa perspectiva, adotamos o critério da autoidentificação defendida por Silva (2011) como um dos princípios da metodologia Mapa Social, assim como por Trindade (2015), que explicita que a autoidentificação das "juventudes" deve partir dos moradores das comunidades pesquisadas.
\end{abstract}

iii A COMPRUP surgiu em 1992 como uma necessidade de fornecer opções de renda para as populações que vivem nas áreas de reforma agrária e em comunidades tradicionais de Poconé, fortalecendo a produção e comercialização dos produtos. A versatilidade do baru ou Cumbaru (Dipterys Alata) árvore nativa do Cerrado, chamou a atenção da cooperativa, que passou a estimular seus associados a se dedicarem à coleta e ao beneficiamento dessa planta, garantindo renda extra para mais de 200 famílias de pequenos agricultores16da região. A cooperativa possui equipamentos (forno, mesa, torradeiras, embaladora, prensa e embalagens) para o beneficiamento do Cumbaru.

iv As discussões de preparação da I Conferência iniciaram-se em agosto de 1997, logo após o I Encontro Nacional dos Educadores e Educadoras da Reforma Agrária (Enera), realizado pelo Movimento dos Trabalhadores Rurais Sem Terra (MST) em julho daquele ano, evento em que algumas entidades desafiaram o MST a levantar uma discussão mais ampla sobre a educação no meio rural no brasileiro (Caldart, 2013, p. 258). 


\author{
Informações do artigo / Article Information \\ Recebido em : 16/01/2020 \\ Aprovado em: 07/04/2020 \\ Publicado em: 13/08/2020 \\ Received on January 16 th, 2020 \\ Accepted on April 07th, 2020 \\ Published on August, 13th, 2020 \\ Contribuições no artigo: As autoras foram as \\ responsáveis por todas as etapas e resultados da \\ pesquisa, a saber: elaboração, análise e interpretação dos \\ dados; escrita e revisão do conteúdo do manuscrito \\ e; aprovação da versão final publicada. \\ Author Contributions: The author were responsible for \\ the designing, delineating, analyzing and interpreting the \\ data, production of the manuscript, critical revision of the \\ content and approval of the final version published.
}

Conflitos de interesse: As autoras declararam não haver nenhum conflito de interesse referente a este artigo.

Conflict of Interest: None reported.

\section{Orcid}

Jucieli Bertoncello

(iD)

http://orcid.org/0000-0003-3750-9874

Michelle Tatiane Jaber da Silva

iD http://orcid.org/0000-0001-6328-5996

\author{
Regina Aparecida da Silva \\ Dttp://orcid.org/0000-0002-2207-8437
}

\section{Como citar este artigo / How to cite this article}

APA

Bertoncello, J., Jaber-Silva, M. T., \& Silva, R. A. (2020). Juventudes Camponesas das Comunidades Zé Alves e Laranjal no Município de Poconé-MT: dilemas entre ficar e sair do campo. Rev. Bras. Educ. Camp., 5, e8255. http://dx.doi.org/10.20873/uft.rbec.e8255

ABNT

BERTONCELLO, J.; JABER-SILVA, M. T.; SILVA, R. A. Juventudes Camponesas das Comunidades Zé Alves e Laranjal no Município de Poconé-MT: dilemas entre ficar e sair do campo. Rev. Bras. Educ. Camp., Tocantinópolis, v. $5, \quad$ e8255, 2020. http://dx.doi.org/10.20873/uft.rbec.e8255 